survey among 300 junior high school students focused on their perceptions of known and unknown walking environments. It enabled to draw up a sensible mapping of their actual walking environment and a qualitative analysis of the elements using to judge the pleasantness and safety and characterise their representations of positive or negative actual and virtual travels as pedestrian.

Conclusions The results allow a better understanding of the phenomena and processes involved in the accident of pedestrian adolescents and to identify measures needed to overcome this problem.

\section{SAVING PEDESTRIAN LIVES IN BANGLADESH: A SUCCESSFUL PILOT TO PREVENT ROAD INJURIES}

${ }^{1}$ Md Mazharul Hoque, ${ }^{2}$ AKM Fazlur Rahman, ${ }^{2}$ MH Md Arif Uddin, ${ }^{3} \mathrm{MC}$ Thierry, ${ }^{3}$ Jasper Vet. ${ }^{1}$ Dean, Faculty of Civil Engineering, and Professor, Department of Civil Engineering, Bangladesh University of Engineering and Technology (BUET), Bangladesh; ${ }^{2}$ Centre for Injury Prevention and Research, Bangladesh (CIPRB), Bangladesh; ${ }^{3}$ Safe Crossings, The Netherlands

\subsection{6/injuryprev-2016-042156.292}

Background Around 90\% of the world's road traffic deaths occur in low and middle income countries (LMIC). Bangladesh has over 100 road traffic deaths per 10,000 motor vehicles, one of the highest rates in the world. Most of the crashes occurring at 'black spots' and about 70\% of crash fatalities occur in rural areas. A pilot project has been implemented on the Dhaka-Sylhet (N2) highway of Bangladesh. This road has many black spots and a high number of pedestrian fatalities. The pilot is innovative in both the selection of implemented interventions (a combination of effective and relatively low-cost measures) and in the approach to monitor pre- and post-intervention data.

Methods The intervention program combines small-scale infrastructural measures for traffic calming (e.g., using speed humps, signs, and marking) with practical training (e.g., to school children) and active community involvement. Three methods are used for monitoring: development of own crash database with local record keepers, speed analysis, and conflict observation study using video (DOCTOR).

Results We understand now the precise causes of crashes and conflicts. Buses are involved in $71 \%$ of dangerous road situations. Speeding and overtaking are the main risk-enhancing factors. After implementation of the pilot, the crash database showed a $63 \%$ reduction in the number of crashes and a reduction of over $70 \%$ in the number of people killed and injured.

Conclusions The selected combinations of interventions is very effective to reduce road deaths and injuries at relatively low-cost. The selected methodologies for monitoring crash data and crash patterns provided a thorough overview and analysis of the causes of crashes and the impact of the selected interventions. Both the interventions and the monitoring methods are suitable for use in other LMICs.

\section{VISION ZERO TO PROMOTE CYCLING MOBILITY IN MEXICAN CITIES}

Alejandra Leal Vallejo. Institute for Transportation and Development Policies, ITDP Mexico

10.1136/injuryprev-2016-042156.293

Background ITDP is an international NGO that promotes sustainable mobility, in Mexico we have been strongly promoting the use of the bicycle as a mode of transportation. This would help in cities that are highly congested and also where people have sedentary lifestyles. Continuously we face the same problem, people are afraid to use the bicycle due to the lack of road safety. The philosophy behind Vision Zero has been helping to develop an integrated strategy to promote safer streets and the conditions to increase the number of bicycle trips.

Methods An international comparative study of different Vision Zero plans was developed, analysing the origin in Sweden, and looking at cases such as the one in New York and San Francisco. Interviews and field work has been developed with strategic actors of Mexico City with the support of international experts on road safety and street design.

Results Vision Zero has been a philosophy which helps to gather efforts from civil society and the government that before were disconnected. The main idea "No loss of life is acceptable" is a strong argument to put the topic on the agenda. A coalition Vision Zero of different groups of civil society in Mexico City has been formed. The concept also brings flexibility to adapt to the contexts of Mexican cities. It has been identified components of street design, regulation, and mobility culture and road safety management. Vision Zero has been promoted from civil society, and now it is a discourse taken by the Mayor, the Ministry of Mobility and the one of Public Safety of Mexico City. It was accomplished the publication of the new transit regulation, where civil society worked together with the government to define better regulation for pedestrians and cyclists. Now, the coalition is defining next actions to advocate for, in order to have an integrated road safety policy with activities, timelines and responsible persons.

Conclusions Vision Zero has gather efforts to reduce deaths in Mexico City from different actors. A Vision Zero Ranking at a national level could help to identify what needs to be done by civil society, the government and private sector in order to be able to say that the city has appropriated this strategy. It will also helped to avoid empty discourses from authority and also the provide elements to empower civil society.

\section{BICYCLE INJURIES IN OSLO: INJURY PATTERN IN 2014 TRENDS SINCE 2003}

${ }^{1}$ Knut Melhuus, ${ }^{2}$ Jakob Linhave, ${ }^{1}$ Henrik Siverts, ${ }^{1}$ Martine Enger, ${ }^{1}$ Malte Schmidt, ${ }^{2}$ Johan Lund. ${ }^{1}$ Oslo University Hospital, Norway; ${ }^{2}$ Norwegian Directorate of Health, Oslo

\subsection{6/injuryprev-2016-042156.294}

Background Interest for bicycling is increasing for transport, and also for health promotion. In cities with demanding traffic pattern, bicycling might be a dangerous activity. Due to lack of knowledge health and traffic authority financed an in-depth investigation of bicycle injuries treated in Oslo University Hospital (OUH), both as in and out patients. Continuous injury monitoring in the AED since 2003 gave possibility to follow trends.

Methods The study was a one-year prospective in-depth investigation with 20 variables. All patients contacting the AED due to a bicycle injury filled in a one-page form with description of 14 variables of the accident and a free text. Health personnel collected relevant information for patients arriving by ambulance and those not able to fill in form themselves. Based on previous studies it is estimated that about $85 \%$ of all injured persons from the Oslo population are treated at $\mathrm{OUH}$.

Results 2184 persons were treated due a bicycle accident in 2014, 71\% were single accidents. $65 \%$ were men. Median age 
was 34 years, for women 32 years. 20\% were head injuries, 33\% fractures, higher than average fracture rate in all injuries. 80 injuries were serious (AIS 3), 8 severe (AIS 4) and 3 critical (AIS 5). $60 \%$ of the injured had used helmet, and got fewer head injuries than those without helmets. $10 \%$ were influenced by alcohol/ drugs. $77 \%(\mathrm{~N}=1673)$ happened in "inner" city, $13 \%$ in wooden areas in the city, $7 \%$ in other municipalities, and $3 \%$ abroad. In $10 \%(\mathrm{~N}=164)$ of injuries in "inner city", tram rails were involved. Police registered 125 bicycle injuries in "inner city" during 2014, 7\% of injuries treated at OUH. Since 2003, population of Oslo has increased by $22 \%$, bicycle injuries by $21 \%$.

Conclusions Incidence of bicycle injuries in the population of Oslo seems to be rather stable during the last 12 years. They are more severe than injuries in average. Patients without helmets have more head injuries than patients with helmets.

\section{CYCLING INFRASTRUCTURE FOR REDUCING CYCLING INJURIES IN CYCLISTS: A COCHRANE REVIEW}

${ }^{1}$ Caroline A Mulvaney, ${ }^{1}$ Sherie Smith, ${ }^{1}$ Michael C Watson, ${ }^{2}$ John Parkin, ${ }^{1}$ Carol Coupland, ${ }^{3}$ Phil Miller, ${ }^{1}$ Denise Kendrick, ${ }^{4}$ Hugh McClintock. ${ }^{1}$ University of Nottingham, UK; ${ }^{2}$ University of the West of England, UK; ${ }^{3}$ Nottingham University Hospitals NHS Trust, UK; ${ }^{4}$ Pedals, UK

\subsection{6/injuryprev-2016-042156.295}

Background Cycling infrastructure aims to make cycling more convenient and safer for cyclists. We undertook a Cochrane review to assess the effectiveness of cycling infrastructure at reducing cycling injuries in cyclists.

Methods Sixteen databases, twelve websites and conference proceedings were searched up to March 2015. Eligible studies included RCTs, CBAs or an ITS evaluating a cycling infrastructure and reporting injuries or collisions. Two authors independently extracted study data and quality assessment.

Results Twenty one studies met inclusion criteria. Meta-analyses relating to cycle lanes on roads (rate ratio (RR) 1.21, 95\% confidence interval (CI): 0.70 to 2.08 ) and cycle routes and networks (RR $0.68,95 \%$ CI: 0.31 to 1.47 ) found no evidence that either were effective at reducing cycle collisions. From a narrative review, there was some evidence that $20 \mathrm{mph}$ speed limits were effective at reducing collisions. Redesigning specific parts of cycle routes that may be particularly busy or complex in terms of traffic movement may reduce the risk of collision. The conversion of intersections with and without signals to roundabouts with cycle paths may reduce the odds of collision. Findings related to the instalment of Advanced Stop Lines, use of colour, cycle tracks and cycle paths suggest these neither reduce nor increase injury collisions in cyclists. There was some evidence that the conversion of intersections to roundabouts with cycle lanes marked as part of the circulating carriageway may increase cycle collisions. There was some evidence that continuing a cycle lane across the mouth of a side road with a give way line onto the main road may increase the risk of injury collisions in cyclists.

Conclusions Several designs of cycling infrastructure may reduce collisions. There is a paucity of high quality evaluations of cycling infrastructure. The use of adequate data collection periods and assessment of cycle flows would improve future evaluations.

\section{6 CYCLIST DEATHS IN LONDON: IMPLICATIONS FROM A SAFE SYSTEMS PERSPECTIVE}

${ }^{1}$ Nicola Christie, ${ }^{2}$ Rachel Talbot, ${ }^{2}$ Steve Reed, ${ }^{2}$ Jo Barnes, ${ }^{2}$ Pete Thomas. ${ }^{1}$ University College London, UK; ${ }^{2}$ Loughborough University, UK

\subsection{6/injuryprev-2016-042156.296}

Background In 2013 the London Mayor committed to increasing cycling levels by $400 \%$ (from 2001) by 2026 . Although the numbers of deaths per year are relatively low cycling in London has become highly politicised with significant media focus on every cycle death in the capital. This study was commissioned by Transport for London to explore contributory factors to cyclist deaths and implications for interventions.

Methods This study involved an in-depth case review of 53 pedal cycle fatalities in London between 2007-2011. Police fatal reports were used in the analysis. The method involved application of a Haddon matrix approach to data analysis and a case by case review by a multidisciplinary team to explore the multifactorial nature of contributory factors from a safe systems perspective.

Results Over half the crashes involved a truck ( $>3.5$ tonnes) as the primary collision partner, most happened during daylight and the commute period, on low speed $(30 \mathrm{mph})$ urban roads and at a junction, particularly at a complex junction. A notable finding was the involvement of trucks in fatalities, particularly for female cyclists, where the truck was turning left. For these crashes contributory factors were identified as poor visibility of the cyclist to the truck driver related to cab design and lack of mirrors, poor positioning by the cyclist and infrastructure issues such as lane narrowing creating a conflict point between cyclist and trucks.

Conclusions Potential countermeasures to mitigate risks for cyclists include the design of trucks to create greater visibility of vulnerable road users, training of both drivers and cyclists to raise awareness of visibility and designing infrastructure and managing traffic to reduce the opportunities of conflicts arising in the first place. Few well designed intervention studies were identified. The overrepresentation of female cyclists in collisions with left turning trucks is an issue that warrants further investigation.

\section{Alcohol, Drugs and Medicines}

\section{Parallel Tue 2.4}

\section{CONCURRENT USE OF ALCOHOL AND MARIJUANA AND FATAL MOTOR VEHICLE CRASHES: A CASE-CONTROL STUDY}

Guohua Li, Stanford Chihuri. Columbia University, USA

\subsection{6/injuryprev-2016-042156.297}

Background About one third of fatally injured drivers in the United States test positive for non-alcohol drugs and 20\% test positive for two or more drugs. Alcohol-marijuana is the most commonly detected poly-drug combination. The role of concurrent use of alcohol and marijuana in crash causation has not been well understood.

Methods Using a case-control design, we assessed the individual and joint effects of alcohol and marijuana on fatal crash risk. Cases $(n=2613)$ were drivers who were involved in fatal motor vehicle crashes in the continental United States during specific time periods in 2006, 2007, and 2008 and controls $(n=7719)$ 